\title{
GENDER PERSPECTIVE IN THE ANALYSIS OF THE RELATIONSHIP BETWEEN HEALTH AND WORK CESSATION, AND HOW TO DEAL WITH IT
}

\author{
ALEKSANDRA PIŁAT ${ }^{1}$, ALEKSANDER GAŁAŚ ${ }^{2}$, MICHAŁ WILGA ${ }^{1}$, MARIA CABELLO ${ }^{3}$, SEPPO KOSKINEN ${ }^{4}$, \\ JOSEP MARIA HARO ${ }^{5}$, MATILDE LEONARDI ${ }^{6}$, and BEATA TOBIASZ-ADAMCZYK ${ }^{1}$
}

${ }^{1}$ Jagiellonian University Medical College, Kraków, Poland

Department of Medical Sociology

${ }^{2}$ Jagiellonian University Medical College, Kraków, Poland

Chair of Epidemiology and Preventive Medicine

${ }^{3}$ Autonomous University of Madrid, Madrid, Spain

Department of Psychiatry

${ }^{4}$ National Institute for Health and Welfare, Helsinki, Finland

${ }^{5}$ Saint John of God Health Park in Barcelona, Barcelona, Spain,

Biomedical Research Networking Center for Mental Health Network (CIBERSAM)

${ }^{6}$ Foundation IRCCS Neurological Institute Carlo Besta, Milan, Italy

\begin{abstract}
Objectives: The main objective of this study is to examine the relationship between health and an early exit from paid employment in the Finnish, Polish, and Spanish populations. The authors have addressed the following 3 issues: who chooses not to work according to gender patterns, whether the health status is a determinant of being non-employed, and what diseases are associated with being non-employed. Material and Methods: The studied material consists of data from the Collaborative Research on Ageing in Europe (COURAGE in Europe) project. The analysis was based on a sample of 5868 individuals, including 1214 from Finland, 2152 from Poland and 2532 from Spain. In the paper, these data were complemented with the results of the PArticipation To Healthy Workplaces And inclusive Strategies in the Work Sector (PATHWAYS) project. Results: The results of the study revealed that self-rated health was a strong predictor of being non-employed for different reasons. Chronic diseases, such as arthritis, angina, diabetes, chronic obstructive pulmonary disease, depression and hypertension, were typically associated with an increased risk of being non-employed due to health problems and early retirement. Women more frequently reported arthritis and depression, while a higher proportion of men suffered from angina and diabetes. Conclusions: The results obtained by the authors highlight the importance of evaluating gender patterns in work cessation and, at the same time, the importance of gender-focused actions in terms of preventing withdrawal from the labor market. In principle, all chronic diseases have some impact on participation in the labor market. It is worth noting, however, that each of them affects workforce participation in a different manner, depending on the specific disease, country and gender. For this reason, tailored support to every individual's needs is highly recommended. Int J Occup Med Environ Health. 2020;33(3):365-84
\end{abstract}

Key words:

self-rated health, unemployment, gender differences, workforce, chronic disease, work cessation

Funding: the study was financed from the financial resources for science in 2016-2018, granted for the implementation of an international co-funded project. This study was supported by the European Union's Health Programme (2014-2020) (grant No. 663474 entitled "PATHWAYS: PArticipation To Healthy Workplaces And inclusive Strategies in the Work Sector," project manager: Matilde Leonardi, Ph.D.) and by the Polish Ministry of Science and Higher Education (grant No. 3649/HP3/16/2017/2, project manager: Prof. Beata Tobiasz-Adamczyk). This study was also supported by the European Community's Seventh Framework Programme (FP7/2007-2013) (grant No. 223071 entitled "The Collaborative Research on Ageing in Europe," project manager: Matilde Leonardi, Ph.D.) and by the Polish Ministry of Science and Higher Education (grant No. 1277/7PR/UE/2009/7, project manager: Prof. Beata Tobiasz-Adamczyk).

Received: April 20, 2018. Accepted: February 25, 2020.

Corresponding author: Aleksandra Piłat, Jagiellonian University Medical College, Department of Medical Sociology, Kopernika 7a, 31-034 Kraków, Poland (e-mail: aleksandra.pilat@uj.edu.pl). 


\section{INTRODUCTION}

In most European countries, workforce ageing and labor shortages are among the most important challenges. In 2030, at the European Union (EU) level, the proportion of mature employees will reach a peak. However, in the case of individual European countries, the intensification of this process will be different in terms of the character and rate. For example, in the coming decades, the share of people aged 45-64 in 12 out of 28 EU countries will reach $\geq 50 \%$, and even $53-54 \%$ in the case of Slovakia, Poland, Romania and Latvia [1]. Most of these people will remain out of paid work or they will withdraw from the labor market prematurely. The decline among women will be even more significant due to different patterns of workforce participation for women and men. Statistically speaking, women are less occupationally active than men. In 2017, among people aged 20-64, the share of working women in Europe reached $66.5 \%$ and the share of working men $-78 \%$. In Spain, for example, $<60 \%$ of women were working compared to $71.5 \%$ of men [2]. For people aged $>50$, these differences are getting even bigger. For example, in Poland, the activity rate for women aged 50-64 in 2017 was $51.1 \%$, and for men $67.2 \%$. Taking into account only people aged $60-64$, this rate was $22.1 \%$ of working women, compared to almost $50 \%$ of working men [3]. Workforce participation depends on many factors. Some of them have been examined by various researchers. Special attention has been paid to both health and chronic conditions, as well as the integration and reintegration into the labor market. People with chronic diseases (PwCDs) (defined by WHO as diseases characterized with long duration and a generally slow progression, which are not transmitted from one person into another) often experience some negative impact on their working life [4]. This dependence has been widely discussed in many research studies and from many perspectives. On the one hand, a systematic review conducted by Rijn et al. [5] revealed that the presence of $\geq 1$ chronic disease was a risk factor for transition into a disability pension or unemployment. On the other hand, a Finnish empirical study [6] exploring unemployment and various aspects of health found that people of poor health were likely to belong to the group of people who eventually become unemployed. Hence, this study stressed that self-rated health (SRH) does not change as such with the occurrence of unemployment.

However, the main focus in this study was on specific diseases, not only on the general health status. The authors limited their review of the existing literature to the analysis of the relationship between specific chronic diseases and the situation on the labor market. For example, a study based on the longitudinal Survey of Health, Ageing and Retirement in Europe (SHARE) data demonstrated the impact of cardiovascular diseases and diabetes on the increased probability of an early exit from paid employment via disability benefits or early retirement and, to a smaller extent, via unemployment or other exit routes [7]. Yet another study by Rumball-Smith et al. [8], which examined the impact of diabetes on leaving the workforce across 16 countries, found that people with diabetes had a $30 \%$ increase in the rate of workforce exit, compared to people without the disease. Moreover, about 1 in 17 cases of nonparticipation in workforce could be attributed to chronic obstructive pulmonary disease (COPD) or asthma [9].

An Australian study which examined the impact of several chronic diseases on the probability of workforce participation confirmed that the impact of such diseases was significant although it differed depending on gender and age [10]. It is well known that morbidity in most chronic diseases also differs according to gender. Firstly, there are some differences in how these diseases affect men and women: it has been stressed that "these diseases and their risk factors are very much influenced by the roles and expectations in the society" [11]. In consequence, women tend to be affected by chronic diseases at younger ages than men, and they live longer with their diseases or disability. For example, epidemiological studies have 
proven that men and women face different risks and have different outcomes with cardiovascular diseases [12]. In European countries, more women than men have been found to suffer from depression, asthma, and high blood pressure [13], while ischemic heart disease is the most frequent cause of death among men [14].

There are also differences between gender, chronic diseases and workforce participation. A study conducted in Australia demonstrated gender patterns in workforce participation among PwCDs: men with depression or arthritis were less likely to work full time, whereas women with depression "preferred" part-time jobs [15]. Tunceli et al. [16], in a longitudinal study focused on the effect of diabetes on the labor market, demonstrated a greater association between diabetes and work-lost days for women than for men.

The health status is the indicator mostly connected with the occupational situation. From the employers' perspective, problems are focused on the cost of accommodation and the lack of knowledge about the needs with respect to workplace adaptation; employers are not aware enough of how to deal with workers with disabilities, and they are afraid of the PwCDs' employment condition [17]. On the part of employees, long-term health problems increase fatigue or the lack of understanding, sometimes also the feeling of shame attributable to diseases and stigmatization [18]. In consequence, PwCDs are less frequently employed than others [19]: only $34 \%$ of them are employed in Europe [20]; among people aged 50-59 in $2013,74 \%$ of men and $63 \%$ women with 1 chronic disease, and $61 \%$ of men, as compared to $48 \%$ of women, with $\geq 2$ chronic diseases, were employed [21]. Furthermore, employees with chronic diseases have fewer opportunities to get a new job once they are made redundant [22].

As previously described, non-communicable diseases (NCDs) have a significant impact on the labor market structure, workers, employers, and the society as a whole: in terms of workforce participation, hours worked, job turn- over and, obviously, early retirement [23]. About 555000 European citizens of working age died of chronic diseases in 2013: assuming that those people would have been occupationally active to the age of 65 at the same employment rate as the rest of the population, and based on the average salary of workers in the EU, this amounts to a yearly loss of EUR 115 billion [21]. In European countries, an average cost of social benefits due to ill-health expenditure on disability and paid sick leaves corresponds to $1.7 \%$ of the gross domestic product [21]. The awareness of this relationship could support policy makers, scientists and advocacy groups in creating solutions and systems focused on the retention of employees at the workplace.

To the best of the authors' knowledge, there have been no comparative data which would identify gender and country patterns of people with specific health conditions, and being out of workforce. Most of the existing studies regarding health and workforce participation are focused only on people approaching their retirement age or on older workers. One of the most important databases covering this group is the SHARE study [24], which is the first multidisciplinary, longitudinal European project of micro data on the health, socio-economic status, and social and family networks of individuals aged $\geq 50$. There is also some research including people of working age. Garcia-Gomez et al. analyzed the relative role that health plays as a determinant of both exit from and entry to paid employment [25]. They found that a health shock (a sudden deterioration to health) was an important factor in the transition from the labor market for both younger and older workers. Most of the existing research concentrates only on 1 disease [26-30] or on a general measure of health, frequently based on SRH [31], and none of them has identified gender patterns as a determinant of unemployment.

\section{Aim}

The main aim of this study is to examine the association between the health condition and an early exit from paid 
employment in the Finnish, Polish and Spanish populations. More precisely, the authors have tried to identify:

- whether men and women decide not to work for different reasons,

- whether the health status is a determinant of being non-employed,

- which diseases are associated with being non-employed.

The outcome of the study is discussed in the light of the innovative approaches to promote the occupational integration and reintegration of $\mathrm{PwCDs}$, and to improve their employability.

\section{MATERIAL AND METHODS}

\section{Study design and sample}

In this paper, data from the Collaborative Research on Ageing in Europe (COURAGE in Europe) project were used. Information was gathered through household interviews, where interviews were conducted face-to-face by computer-assisted personal interviewing (CAPI). All the interviewers participated in a training course for the administration of the survey. Quality control procedures were implemented during fieldwork. The study sample size covered 10800 individuals aged $>18$, in total: Finland $(\mathrm{N}=1976)$, Poland $(\mathrm{N}=4071)$ and Spain $(\mathrm{N}=4753)$. The authors used a stratified multi-stage random sampling method. In Poland and Spain, the respondents were randomly selected from among the inhabitants of households from a certain age group, according to the geographical administrative regions and the number of people living there. In Finland, the design was a stratified 2-stage cluster sampling design, and the strata were created based on the largest cities and university hospital regions. A systematic sampling of people was conducted so that the sample size in each stratum was proportional to the corresponding population base. The response rate was 53.4\% for Finland, 66.5\% for Poland and $69.9 \%$ for Spain. These countries were selected to broadly represent different European regions, representing the north, the east and the south of Europe, respectively, taking into consideration their population and health characteristics [32]. In the paper, 1111 subjects out of the whole sample were excluded due to the fact that they had never worked. Next, 3691 were excluded as they were not in the working age category. Due to the Polish legal solutions regarding retirement age ( 65 for men and 60 for women), the authors adjusted working age to 18-59 for Polish women. For women in Finland and Spain, as well as for men in every analyzed country, working age was defined as 18-64. Finally, the sample size available for the research purposes was 5898 individuals, including 1214 from Finland, 2152 from Poland and 2532 from Spain. The unemployment rate among those included in the study was 32\% in Finland, 40\% in Poland and 47\% in Spain. More details are presented in Figure 1.

Data from the COURAGE in Europe project were complemented in the discussion section with results of the PArticipation To Healthy Workplaces And inclusive Strategies in the Work Sector (PATHWAYS) project. The general aim of the PATHWAYS project was to identify innovative strategies to adapt the workplace to the needs of PwCDs, and to improve their integration and reintegration into the workplace.

The COURAGE in Europe project (that interviewed nationally representative samples of adult populations from 3 European countries: Finland, Poland and Spain) constituted a trigger to this study. The COURAGE in Europe project was scientific, quantitative research, whereas the PATHWAYS project was more focused on practical solutions: providing useful insights for a more inclusive labor market. Both projects contained data according to chronic diseases; somatic and mental, as well as occupational situations of people suffering from chronic diseases in European countries.

\section{Measures \\ Health status \\ Based on the COURAGE in Europe project dataset, the following 7 common chronic diseases which impact}




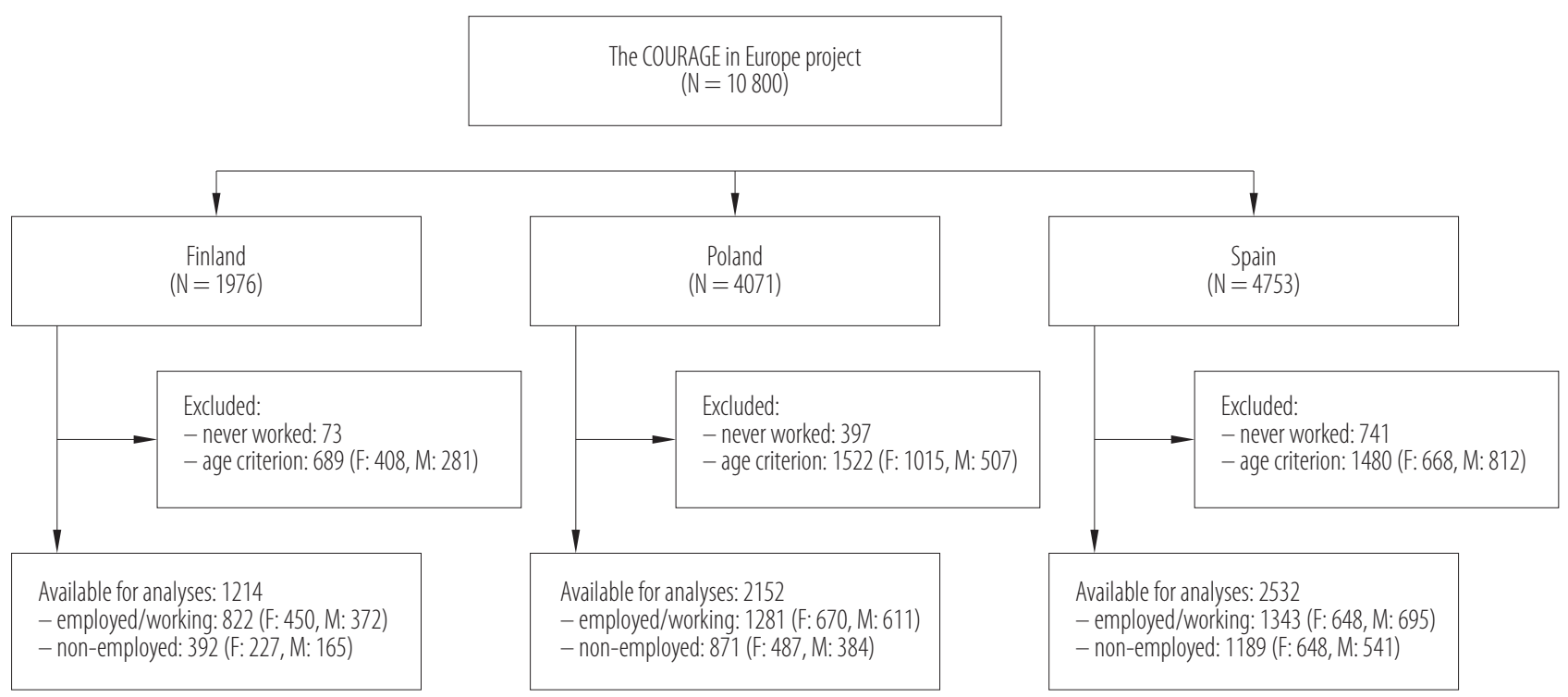

Figure 1. The design of the Collaborative Research on Ageing in Europe (COURAGE in Europe) project (2009-2012)

on work ability were selected: diabetes, rheumatic diseases, hypertension, COPD, as well as asthma, heart diseases, and depression. The respondents were asked to indicate any chronic diseases they had ever been diagnosed with. The question about those diseases was: "Have you ever been diagnosed with/told you have: arthritis/a heart disease/diabetes/chronic lung disease/asthma/high blood pressure/depression?" If the respondents answered "Yes," they were considered to have the disease.

The diseases analyzed in the PATHWAYS project were: musculoskeletal disorders (back and neck pain), mental health conditions (depression), metabolic disorders and diabetes, cardiovascular diseases, respiratory diseases, and neurological diseases (migraine). They were selected based on their contribution to the years lost due to disability (YLDs) in Europe in 2015 [33], and they were similar (except neurological diseases and hypertension, and with a difference between musculoskeletal disorders in the PATHWAYS project and arthritis in the COURAGE in Europe project) to those analyzed in the COURAGE in Europe project.
Self-rated health data from the COURAGE in Europe project In the study, SRH was also taken into account. It was elicited by the following question: "In general, how would you rate your health today?" The answer was assessed on a 5-pt scale, from the best ("very good" - 1) to the worst (“very poor" -5).

\section{Employment status - \\ data from the COURAGE in Europe project}

Firstly, the authors excluded from their analysis people who had never been working; more precisely, those who answered "No" to the question: "As you know, some people take up jobs for which they are paid in cash or in-kind. Other people sell things. Have you ever in your life done any type of work (not including housework)?" Therefore, the non-employed outcome was defined by the dichotomous question: "Have you worked for at least 2 days during the last 7 days?" Between "No" responses, exclusions were performed for the student category, voluntary job, no economic need, and no permission. The category of 
seasonal work was added to the working people group. Then, self-defined reasons for being non-employed were classified into 5 categories: being a homemaker instead of being employed, being non-employed due to care providing, being non-employed due to difficulties in finding a job, being non-employed due to early retirement, and being non-employed for other reasons.

\section{Statistical analysis}

Basic characteristics of the participants included in the analyses have been presented separately for women and men across the 3 countries considered (Finland, Poland and Spain). Differences between men and women were tested by the $\chi^{2}$ test as all the analyses fulfilled the expected value $\geq 5$ criterion. The risk of being non-employed was estimated by logistic regression models. The models calculate the relative odds (the odds ratio [OR]) for the outcome of interest among the defined group, as compared to the reference group. The OR was used as a proxy measure of withdrawal (being non-employed) from the labor market. Different outcomes were considered, i.e.:

- being a homemaker instead of being employed,

- being non-employed due to care providing,

- being non-employed due to difficulties in finding a job,

- being non-employed due to early retirement,

- being non-employed for other reasons.

The risk was estimated for different SRH levels with the reference group of individuals who reported their health as very good by the ordinal logistic regression models. The second part of the analyses focused on the association between the diagnosis of a specific disease (with no disease as a reference) and being non-employed by the nominal logistic regression. The results are presented as ORs and 95\% confidence interval (CI) limits. The significance of variables in the model was based on the Wald statistic. Results with the p-value of $<5 \%$ were considered statistically significant. All the analyses were performed using IBM SPSS Statistics version 24 for Windows.

\section{RESULTS}

Considering SRH, a statistically significant difference between gender groups was observed only in Poland, and there were fewer women than men who reported having a poor and very poor health status. The health status was also assessed by physicians who reported the presence of diagnosed diseases. The observed pattern was very similar in each of the analyzed countries. Women more frequently reported arthritis and depression, but a higher proportion of men had angina and diabetes. There were also some country-specific differences, as COPD was observed more frequently among men in Poland only, and high blood pressure was reported by a higher proportion of men in Poland, compared to a higher proportion of women in Spain (Table 1).

Some details about employment and the current working status are presented in Table 2. A higher proportion of working men, compared to women, was observed in Spain, and also in 2 other countries the direction of the difference was the same, although it was statistically insignificant. The distribution of reasons for being non-employed also varied in the 3 countries under analysis. The main reason in Finland was early retirement for both women and men; in Poland, it was health problems in women and early retirement in men, and in Spain difficulties in finding a job for both women and men (Table 2). The distribution of other reasons for being non-employed showed that more women than men declared being homemakers as an argument for not being occupationally active in Finland (4.6\% vs. $0.4 \%)$, in Poland (6.8\% vs. $1.6 \%)$ and also in Spain (14.4\% vs. $0 \%)$. Care providing as the reason for being non-employed was much more common among women in Poland (2.4\%) and Spain (3.2\%).

In the second part of the statistical analyses, the authors tried to reveal whether the health status was a determinant of being non-employed for a specified reason (so, if a person was non-employed due to difficulties in finding a job, the analysis tried to answer whether this fact was 
somehow linked with the person's health status, i.e., to check if health deterioration increased the probability of being non-employed due to difficulties in finding a job). As regards being a homemaker instead of being employed, health deterioration decreased the probability of this outcome in Finnish women, and in Polish women and men. However, a reverse effect was observed for Spanish women, among whom a worse health status increased the probability of being a homemaker in that group. No associations were observed between being non-employed due to care providing and the health status of the respondents. Typically, health deterioration was linked to the increase in the risk of being non-employed due to difficulties in finding a job.

Significant trends showing a continuous increase in the risk across health categories, from very good to poor or very poor, was observed in Finnish women, Polish men and women, and Spanish men and women. Moreover, a poor health status was a very strong predictor of being non-employed among women in Finland $(\mathrm{OR}=13.87$, 95\% CI: 2.28-84.2) and in Poland (OR $=11.4,95 \%$ CI: 3.11-42.0). The number of individuals reporting very poor health in the study population was too small to perform reliable analyses in the majority of the analyzed subgroups, except men in Poland among whom it was found that very poor health increased the risk of being non-employed due to difficulties in finding a job by approx. 20 times. The other part of data just confirmed these expectations, showing a clear association between a decrease in the subjective health status and an increased risk of being non-employed due to health problems. In addition, a strong significant association was observed in each of the analyzed groups across all the countries under consideration.

Finally, the authors addressed the question of how SRH influenced the risk of being non-employed due to early retirement. People with deteriorated health were more likely to start their retirement earlier. The risk of being non-employed for this reason among individuals with poor health was almost 5 times higher among men in Finland and Spain, and 16 times higher among men in Poland. As regards women, the risk of being non-employed due to early retirement associated with poor health (as compared with women with very good health), was 6 times higher in Finland, 12 times higher in Poland, and $>18$ times higher in Spain. Very poor health had an even stronger effect (Table 3).

As the last part of their investigation, the authors performed analyses to determine which diseases were associated with being non-employed for different reasons. The first reason, i.e., being a homemaker instead of being employed, was linked only with arthritis, but this disease increased the risk of being non-employed only among women in Spain (OR = 2.24, 95\% CI: 1.49-3.34). There were no associations between different diseases and being non-employed due to care providing for the majority of diseases except hypertension among women in Spain (OR $=3.38,95 \%$ CI: $1.68-6.80)$.

Considering the risk of being non-employed due to difficulties in finding a job among women in Finland, diabetes, depression and hypertension were the conditions associated with an increase (Table 4). Hypertension was the only statistically significant factor for men in Finland and for women in Poland. In Spain, diseases which were significantly linked with this outcome included arthritis, depression and hypertension in women, and diabetes in men. The diagnoses of arthritis, angina, diabetes, COPD (except in Finland), as well as depression and hypertension, were typically associated with an increased risk of being non-employed due to health problems. The disease which failed to show any association was asthma, which was significant only among men in Spain (Table 4). All the aforementioned diseases were also somehow linked with an increased risk of being non-employed due to early retirement. The strongest predictor in Finland was angina for both gender groups; in Poland, it was diabetes for women and hypertension for men, and in Spain hyperten- 


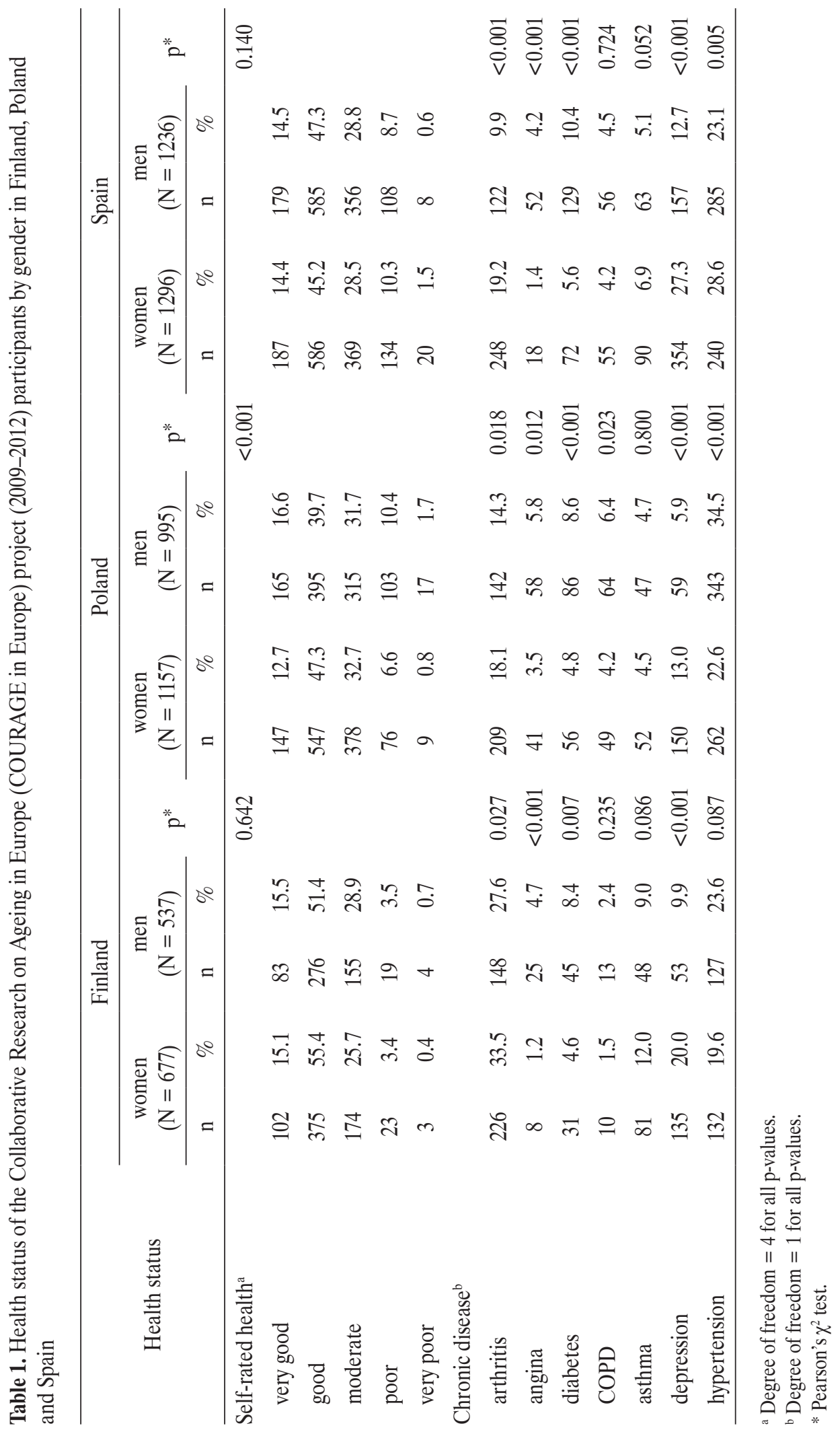




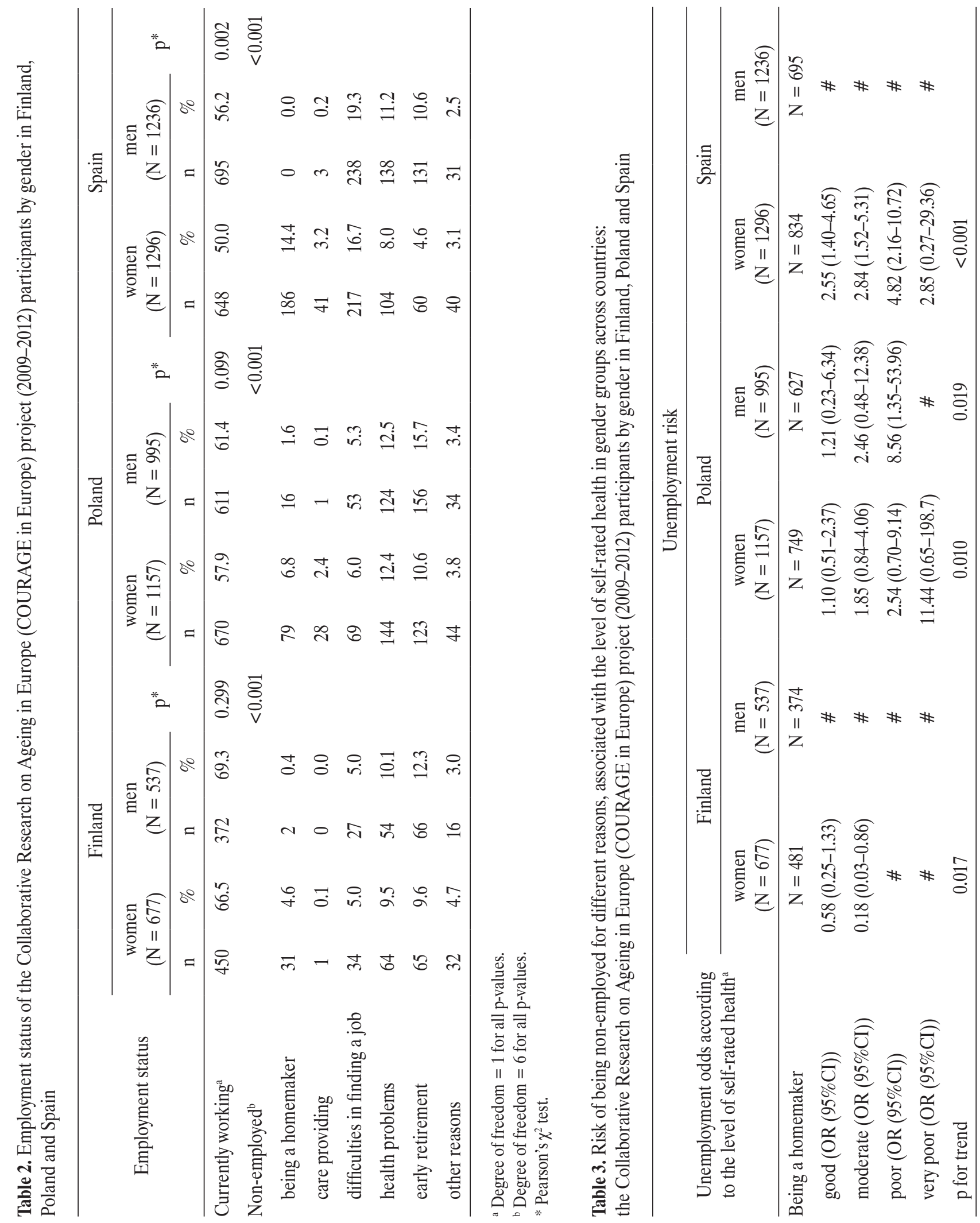




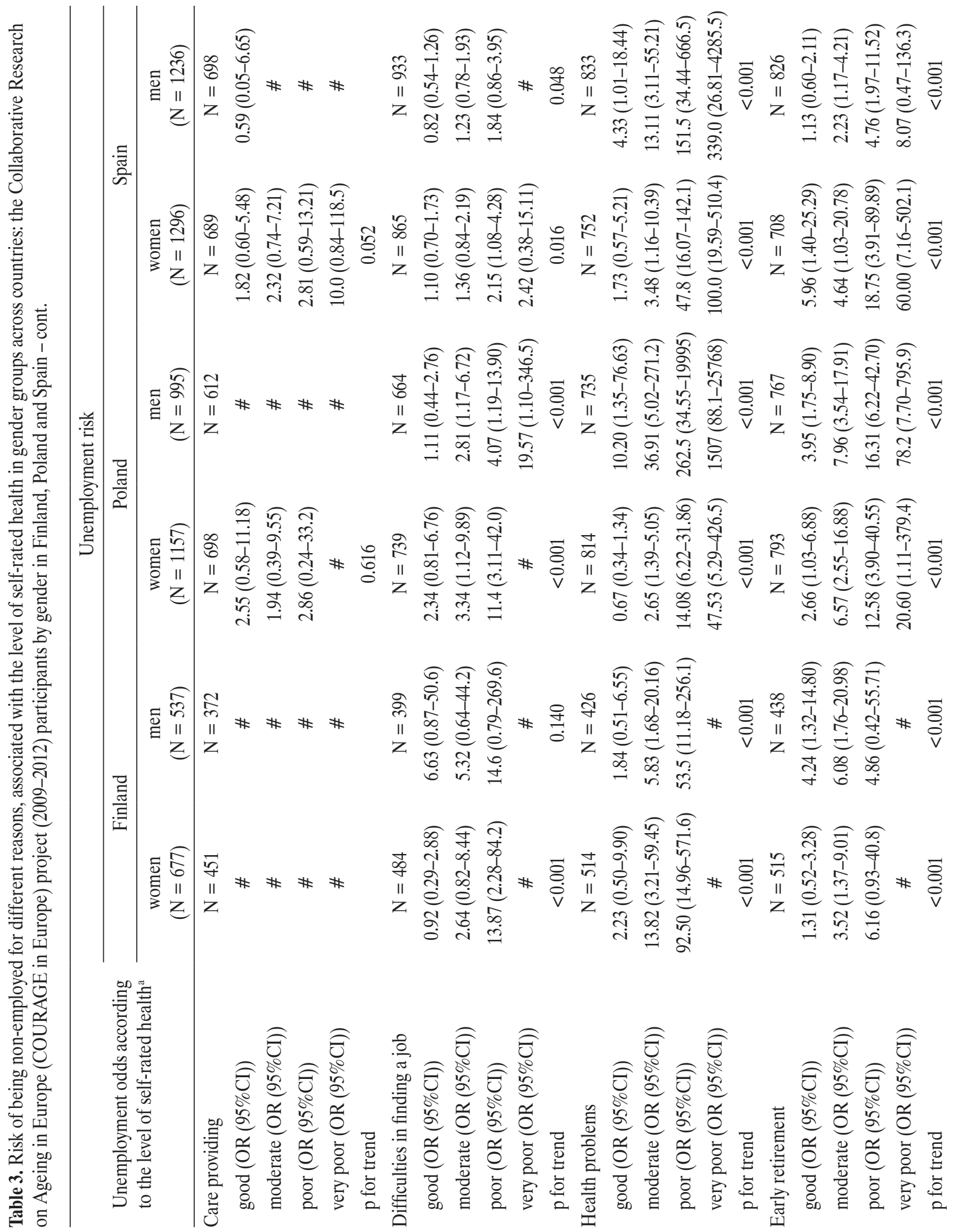




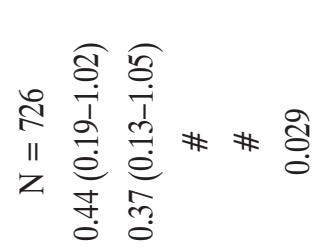

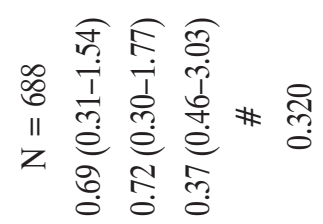

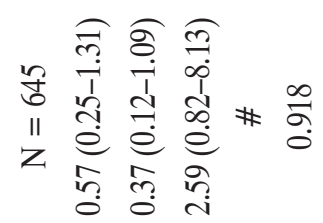

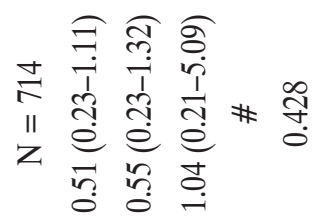

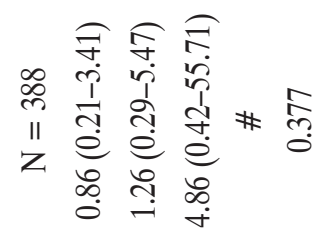

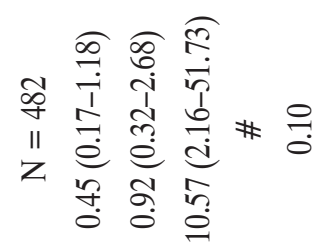

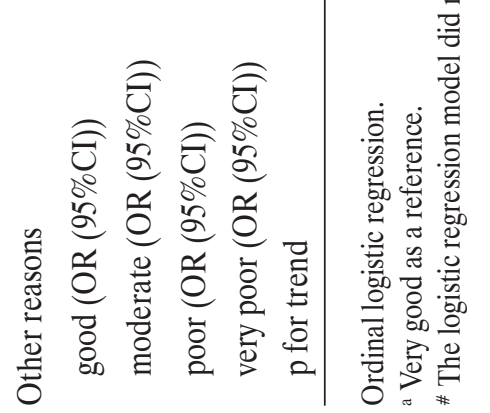

造

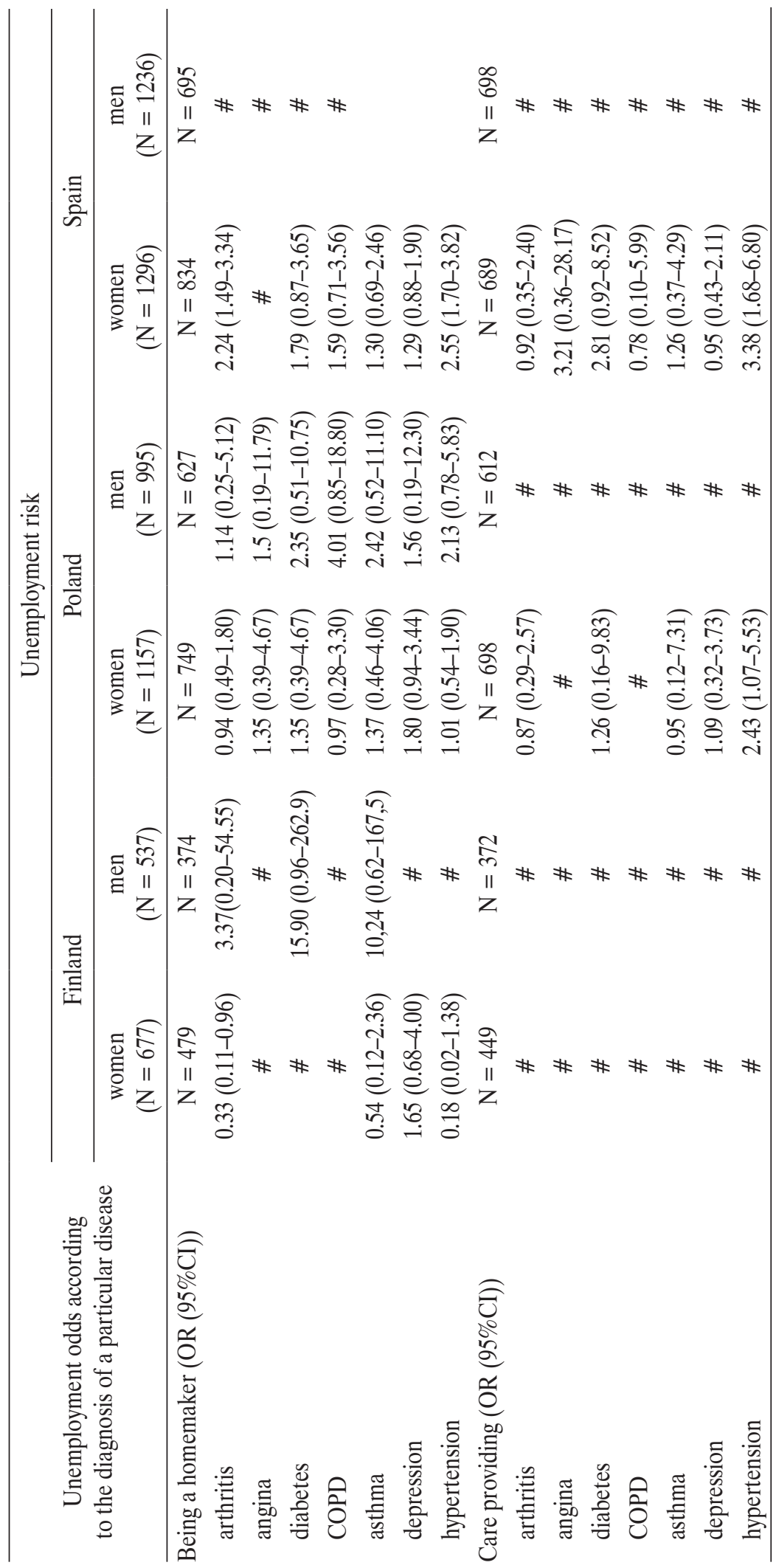




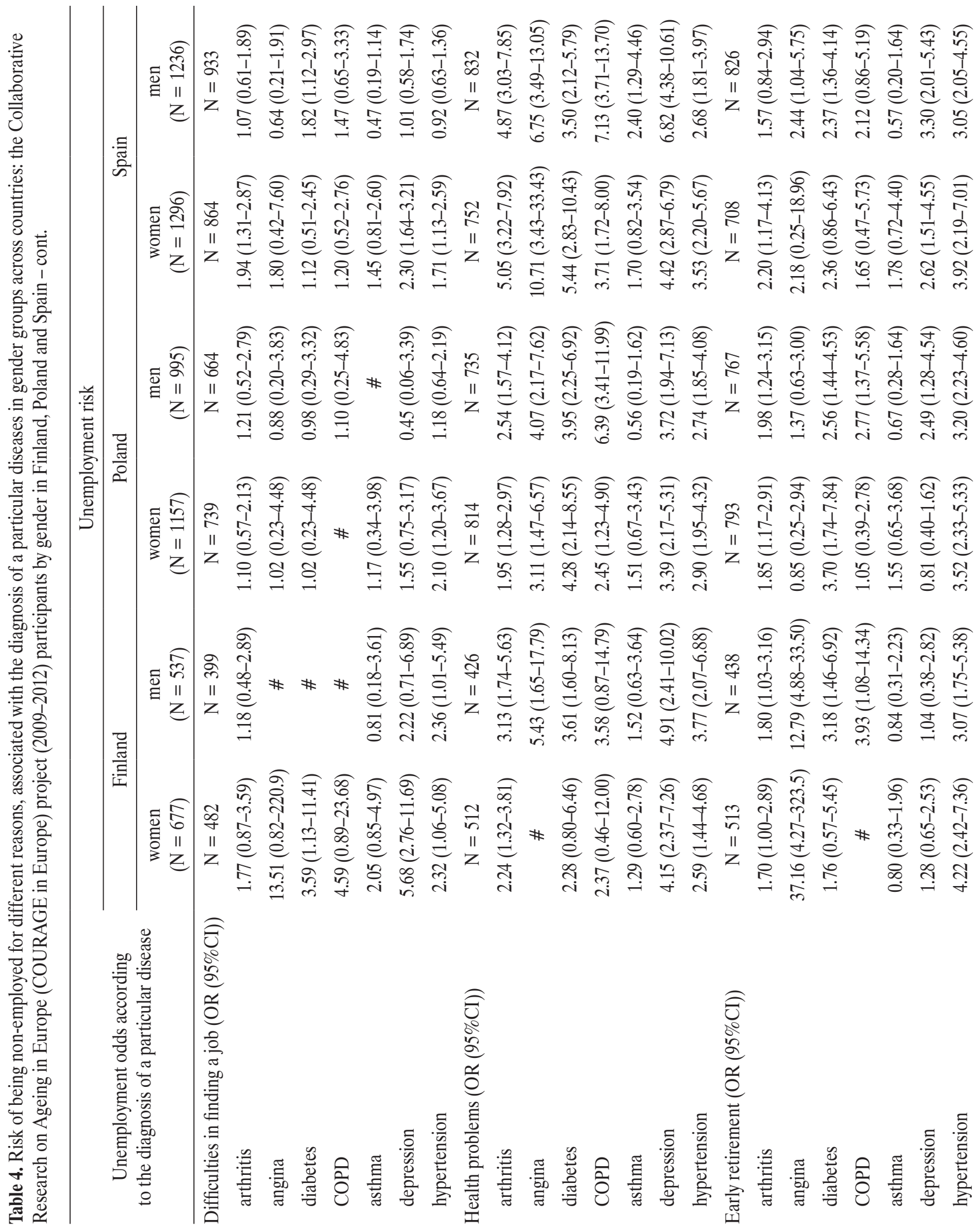



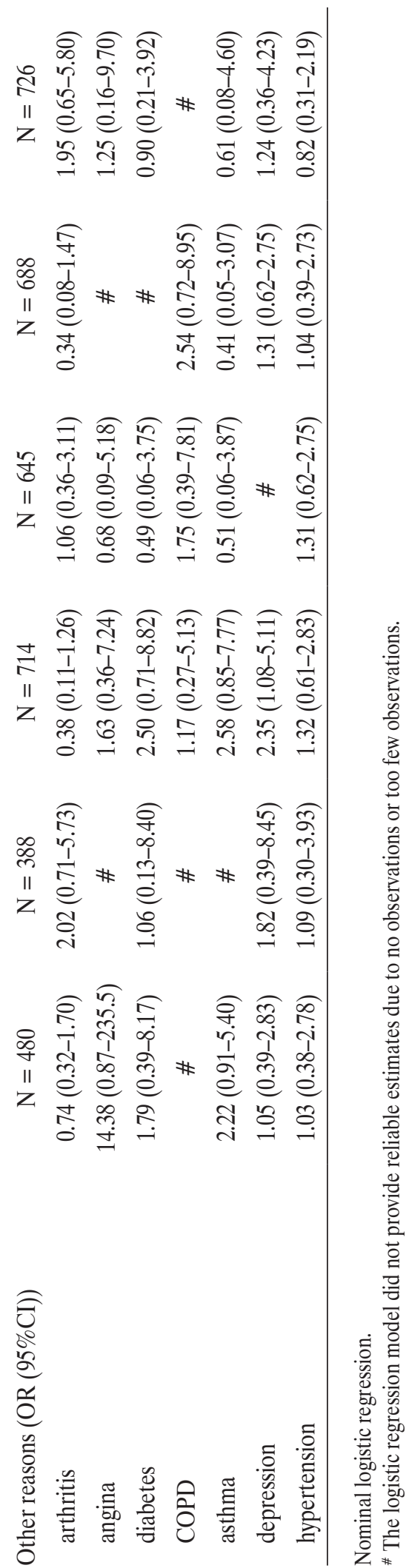

sion for women and depression for men. The only disease which did not show any significant effect either in women or in men, in any of the countries under consideration, was asthma (Table 4).

\section{DISCUSSION}

The results of the COURAGE in Europe project indicated that having a long-term chronic disease increased the probability of withdrawing from or never entering the labor market. The PATHWAYS project focused on innovative strategies that could improve the participation of PwCDs in the labor market. This study showed that the effects of the health status on various forms of unemployment were significant, but different for women and men. The results obtained by the authors highlighted the importance of gender patterns in work cessation. Women more often declared chronic diseases, while men rated their health worse than women. A difference was observed also in terms of the reasons of being non-employed and genders. Chronic health conditions as well as poor SRH were related to people's decisions of withdrawal from the labor market.

Diseases evaluated in both projects, such as depression, a heart disease, COPD or diabetes, have some relevant implications for the labor market structure in terms of the employment rate/withdrawal from/no entry to the labor market. As the authors were able to prove, these effects strongly differ between countries and genders.

The authors observed a strong effect of SRH as a reason for being non-employed. Perceiving one's health as poor, or in some cases as very poor, demonstrated even stronger associations than any of the long-term diseases under analysis. Those respondents who assessed their health mostly as moderate had more odds for not being occupationally active for most of the reasons under consideration. The relationship between poor or very poor SRH and being non-employed was noticed in every country, for both women and men. It also constituted an important factor as 
regards difficulties in finding a job in the Polish workforce in general, and in the Finnish and Spanish women. For early retirement decisions, poor SRH played an important role in Finland, Poland and Spain.

In accordance with the findings of this study, a past study confirmed that poor subjective health was a strong predictor of various types of non-participation in workforce. Schuring et al. found that in European countries poor health was a risk factor for remaining unemployed, becoming unemployed or retiring [31]. Evidence from the Finnish panel data demonstrated that persons who declared poor SRH, regardless of the reason, were likely to belong to the group of unemployed [6]. Van den Berg et al. presented the crucial role of SRH for disability pensions and unemployment [34], and their results are in line with these findings. Research conducted in 10 European countries, including Spain, confirmed a poor SRH impact on different exit routes from the labor market: being unemployed, being retired, or taking care of a household [35]. Contrary to this study, Alavinia and Burdorf did not include Finland and Poland, so not all the results could be compared. However, another research based on a Finnish cohort of men demonstrated that poor SRH was a strong predictor for non-illness-based early retirement [36]. This research just confirmed these findings: in every analyzed country, SRH was crucial for early retirement decisions. This effect was observed despite the discrepancy between countries with respect to retirement age, as well as different attitudes to retirement. For example, retirement age in Poland is one of the lowest in Europe. According to the Organisation for Economic Cooperation and Development (OECD) data, the average age of Poles who withdraw from the labor market is 62.6 for men, and 59.8 for women [37]. In the case of both genders, Poland is rated among the countries where people decide to retire at the youngest age.

Nevertheless, the direction of the relationship between $\mathrm{SRH}$ and being non-employed is not obvious: perceiving health as poor has also been reported as a consequence of becoming non-employed [38]. For example, in a Swedish longitudinal study, SRH was found to decrease together with job loss [39]. Another case was demonstrated in a 2-year follow-up study among older U.S. workers which confirmed that, with the advent of unemployment, the risk of depressive symptoms increased [40]. Declaring poor health, especially among non-employed men of working age, could also be a way of justifying one' workforce status. This thesis, commonly referred to as the "justification assumption," has been confirmed in many studies [41-43]. A review of the existing literature on employment and the health status has highlighted that having a long-term chronic disease constitutes a risk factor for not entering the workforce, or for becoming unemployed or non-employed. The results of the PATHWAYS project revealed that the factors having a negative impact for the PwCDs' occupational situation are: workplace, work structure and schedule, as well as workload [44]. A community-based study conducted in the UK provided evidence for longterm diseases and job loss, especially among those who suffer from musculoskeletal disorders and mental illnesses [45]. Research conducted on Belgian middle-aged workers demonstrated the importance of the work environment in the attendance behavior of individual workers [46]. The results of the PATHWAYS project showed that a modification of work-related aspects, such as the adaptation of working hours, working tasks and workload, could improve the situation of PwCDs on the labor market [47]. Those work-related aspects correspond to the most frequent needs declared by PwCDs [44]. In turn, national and European stakeholders emphasize the need to focus on the capacity of PwCDs rather than on their inability, as well as to develop a more integrated system of the integration and reintegration of people with NCDs [45]. These solutions indicate that a more holistic approach to PwCDs, along with the focus on individual needs, could constrain the withdrawal from the labor market. The adaptation of 
the workplace and of workload to the capacity and needs of an individual should encourage him/her to remain occupationally active.

When studying the relationship between being non-employed or unemployed, and having mental health problems, especially depression, the literature has mostly focused on the influence of job loss on the development of depression [48,49], or on work-related factors and the development of depression [50-53]. Limited evidence suggests that individuals suffering from depression have more odds for being occupationally inactive. The results of the SHARE study based on the population of older workers have shown that depression is the most important health problem associated with workforce exit [35]. Data for a younger cohort (the Coronary Artery Risk Development in Young Adults - CARDIA study) also indicate the associations between depressive symptoms and unemployment [49]. Also these findings show depression as an important factor contributing to not being occupationally active in Spain and Finland.

Until recently, mentioning depression constituted a taboo in the Polish society. This could be one of the reasons for the lack of the relationship between this disease and workforce participation in this study. Actually, depression in Poland is one of the most common reasons for absenteeism: only in the first half of 2016, due to mental disorders, Poles took up to 9.5 million days off work. In the PATHWAYS project, much attention was paid to mental health problems. The category of working dissonance was indicated as the most disturbing factor, according to people with mental disorders. This category consists in the fact that people distance themselves from colleagues, which is likely to lead to social isolation [44]. To reduce absenteeism due to mental health problems, factors influencing effectiveness strategies were identified in the PATHWAYS project. One of the most important strategies, in the stakeholders' opinion, was the integration of employment services with the mental healthcare team [54], as well as interventions tailored to individual needs, which was also found in previous literature [55].

Comparing the results for men and women showed only minor discrepancies. Slight differences between genders were also demonstrated in a study conducted in Denmark, and they were mostly focused on sick absences and women's pregnancies [56]. This research revealed a rather significant relationship between the presence of longterms chronic diseases and workforce participation. For example, arthritis was significant only for women in Spain as regards being a homemaker, while hypertension was a significant factor for men in Finland and for women in Poland.

\section{Strengths and limitations of the study}

In the paper, the authors used 2 separate studies performed in European countries, focusing on the role of different determinants of specific chronic diseases on the occupational situation. They used the results of the COURAGE in Europe project as the background for the practical implementation of the PATHWAYS project. The strength of this study includes the use of community-representative data, with a wide sample of people of working age from 3 different countries. The sample varied with respect to factors such as gender, place of residence, marital status and socio-economic backgrounds. The authors also used the results of other European projects, in addition to the COURAGE in Europe project results. The analysis conducted in this study has a number of advantages with respect to the impact of diseases and work. The authors used specific diseases as potential risk factors of labor market performance. This study also included a subjective health assessment, which could be even more sensitive in health monitoring than external measures of health [57]. Nevertheless, some limitations must be taken into account in this study. The major limitation is related to the crosssectional analysis and self-reported data, which precludes the authors from making an inference about any causal 
relationship. It is especially important due to the ill-health direction: the cross-sectional data do not permit any further explanation whether the health condition determines being non-employed, or whether health is a consequence of withdrawing from workforce. The association between poor health and unemployment may also partly reflect a reverse causation (unemployment may lead to health-endangering behavior and environment) or/and a common background, such as poverty and a low level of education (poverty and a low level of education increase the risk of poor health $[58,59]$ as well as the risk of exit from paid work [60]). The authors were unable to include information about the formal lack of employment due to a small proportion of respondents who answered questions regarding the time when they started and finished their careers.

\section{CONCLUSIONS}

In conclusion, the results of the COURAGE in Europe project suggest that the presence of chronic conditions as well as low SRH increase the probability of an early withdrawal from the labor market. The reverse effect was found to differ among specific chronic diseases countries, and especially gender. These findings supplement the suggested actions of the PATHWAYS project.

The shrinking labor market resources have their main causes in ageing populations, the trend of early retirement, as well as the growing number of chronic diseases and people with disabilities. The first practical policy recommendation from the study is a holistic approach to the problem. It is highly recommended to educate people in the field of old age and diseases. There is a need to raise social awareness of the characteristics of people's needs depending on specific diseases, and to understand how to deal with them. The other issue which should be raised is the importance and possibility of continuing work despite old age and/or chronic diseases. Such interventions could include courses on active ageing, work value, as well as the specificity of the most popular chronic diseases, such as diabetes, depression, heart diseases, and others. The lack of awareness could cause a fear of employing PwCDs, also leading to the reluctance of PwCDs to enter or return to the labor market.

The study implies that policy makers and employers should focus on people's needs and develop strategies such as creating a healthy workplace. It is also imperative to pay special attention to gender differences. As can be assumed based on the results of the PATHWAYS project, the possibility of having flexible working conditions, one of the most requested facilitators to stay at work/remain at work/enter workforce, would probably increase the number of active employees with chronic conditions among the workforce. This will increase the importance of fighting stigmatization, and changing the attitudes of managers and colleagues towards PwCDs [44]. These changes could become preventive measures of the employees' withdrawal from the labor market, especially in terms of early retirement decisions and the increase in long-term health problems.

\section{ACKNOWLEDGMENTS}

The authors would like to thank the whole PATHWAYS and COURAGE in Europe projects' Consortium.

\section{REFERENCES}

1. Szukalski P. [Workforce ageing in Europe - is the process reaching all economic sectors to the same extent?]. Acta Univ Lodz Folia Oeconomica. 2013;291:55-69. Polish.

2. Eurostat [Internet]. Brussels: Eurostat; 2018 [cited 2019 Mar 28]. [Employment statistics]. Available from: https:// ec.europa.eu/eurostat/statistics-explained/index.php?title= Employment_statistics.

3. Eurostat [Internet]. Brussels: Eurostat; 2018 [cited 2019 Mar 28]. [Activity rates by sex, age and educational attainment level (\%)]. Available from: https://ec.europa.eu/eurostat/web/products-datasets/product?code=lfsq_argaed. 
4. Leonardi M, Scaratti C. Employment and People with Non Communicable Chronic Diseases: PATHWAYS Recommendations and Suggested Actions for Implementing an Inclusive Labour Market for All and Health in All Sectors. Int J Environ Res Public Health. 2018;15(8):1674, https://doi. org/10.3390/ijerph15081674.

5. Van Rijn RM, Robroek SJ, Brouwer S, Burdorf A. Influence of poor health on exit from paid employment: a systematic review. Occup Environ Med. 2014;71(4):295-301, https:// doi.org/10.1136/oemed-2013-101591.

6. Petri B, Pekka I. Unemployment and self-assessed health: evidence from panel data. Health Econ. 2009;18:161-79.

7. Kouwenhoven-Pasmooij TA, Burdorf A, Roos-Hesselink JW, Hunink MG, Robroek SJ. Cardiovascular disease, diabetes and early exit from paid employment in Europe; the impact of work-related factors. Int J Cardiol. 2016;215:332-7, https:// doi.org/10.1016/j.ijcard.2016.04.090.

8. Rumball-Smith J, Barthold D, Nandi A, Heymann J. Diabetes Associated With Early Labor-Force Exit: A Comparison Of Sixteen High-Income Countries. Health Aff. 2014;33(1):110-5, https://doi.org/10.1377/hlthaff.2013.0518.

9. Eisner MD, Yelin EH, Trupin L, Blanc PD. The influence of chronic respiratory conditions on health status and work disability. Am J Public Health. 2002;92(9):1506-13.

10. Zhang X, Zhao X, Harris A. Chronic diseases and labour force participation in Australia. J Health Econ. 2009;28:91-108.

11. Pan American Health Organization and World Health Organization [Internet]. Paramaribo: The Organization; 2011 [cited 2019 Apr 1]. PAHO Suriname - Women and Men Face Different Chronic Disease Risks. Available from: https://www.paho.org/sur/index.php?option=com_conten $\mathrm{t} \&$ view $=$ article \&id = 296: women-and-men-face-differentchronic-disease-risks\&Itemid $=477$.

12. Regitz-Zagrosek V. Sex and gender differences in health. Science and Society Series on Sex and Science. EMBO Rep. 2012;13(7):596-603, https://doi.org/10.1038/embor.2012.87.

13. Eurostat [Internet]. Brussels: Eurostat; 2018 [cited 2019 Mar 22]. [Eurostat-Data Explorer: Persons reporting a chro- nic disease, by disease, sex, age and educational attainment level]. Available from: http://appsso.eurostat.ec.europa.eu/ nui/show.do?dataset $=$ hlth_ehis_cd1e\&lang $=$ en .

14. Eurostat [Internet]. Brussels: Eurostat; 2015 [cited 2019 Mar 28]. [Causes of death - standardised death rate]. Available from: https://ec.europa.eu/eurostat/statistics-explained/ index.php?title=File:Causes_of_death_\%E2\%80\%94_ standardised_death_rate,_EU-28,_2015_(per_100_000_inhabitants)_HLTH18.png.

15. Majeed T, Forder PM, Mishra G, Kendig H, Byles JE. Exploring Workforce Participation Patterns and Chronic Diseases Among Middle-Aged Australian Men and Women Over the Life Course. J Aging Health. 2017;9(2):343-61, https://doi.org/10.1177/0898264316635586.

16. Tunceli K, Bradley CJ, Nerenz D, Williams LK, Pladevall M, Elston Lafata J. The Impact of Diabetes on Employment and Work Productivity. Diabetes Care. 2005;28(11): 2662-7.

17. Kaye HS, Jans LH, Jones EC. Why Don't Employers Hire and Retain Workers with Disabilities. J Occup Rehabil. 2011;21(4):526-36, https://doi.org/10.1007//10926-011-9302-8.

18. Varekamp I, Verbeek JH, van Dijk FJ. How can we help employees with chronic diseases to stay at work? A review of interventions aimed at job retention and based on an empowerment perspective. Int Arch Occup Environ Health. 2006;80(2):87-97, https://doi.org/10.1007/s00420-006-0112-9.

19. Oortwijn W, Nelissen E, Adamini S, van den Heuvel S, Geuskens G, Burdof L. Social determinants state of the art reviews - Health of people of working age - Full Report. Luxemburg: European Commission Directorate General for Health and Consumers; 2011.

20. Corral A, Durán J, Isusi I. Employment opportunities for people with chronic diseases. Dublin: IKEI Research and Consulting, European Foundation for the Improvement of Living and Working Conditions; 2014.

21. Organisation for Economic Co-operation and Development [Internet]. Paris: The Organisation; 2016 [cited 2019 Apr 1]. [Health at Glance: Europe 2016: State of Health in the EU 
cycle]. Avaliable from: http://www.oecd.org/health/healthat-a-glance-europe-23056088.htm.

22. Stewart JM. The impact of health status on the duration of unemployment spells and the implications for studies of the impact of unemployment on health status. J Health Econ. 2001;20(5):781-96, https://doi.org/10.1016/S0167-6296(01) 00087-X.

23. European Chronic Diseases Alliance [Internet]. Brussels: The Alliance; 2018 [cited 2019 Apr 1]. Avaliable from: https://alliancechronicdiseases.org/.

24. The Survey of Health, Ageing and Retirement in Europe (SHARE) [Internet]. Munich; SHARE-ERIC; 2019 [cited 2018 Aug 4]. Available from: http://www.share-project.org/.

25. García-Gómez P, Jones AM, Rice N. Health effects on labour market exits and entries. Labour Econ. 2010;17(1):6276, https://doi.org/10.1016/j.labeco.2009.04.004.

26. Kraut A, Walld R, Tate R, Mustard C. Impact of diabetes on employment and income in Manitoba, Canada. Diabetes Care. 2001;24(1):64-8, https://doi.org/10.2337/diacare. 24.1.64.

27. Lerner D, Adler DA, Chang H, Lapitsky L, Hood MY, Perissinotto C, et al. Unemployment, Job Retention, and Productivity Loss Among Employees With Depression. Psychiatr Serv. 2004;55(12):1371-8, https://doi.org/10.1176/appi.ps.55.12.1371.

28. Tunceli K, Bradley CJ, Nerenz D, Williams LK, Pladevall M, Elston Lafata J. The impact of diabetes on employment and work productivity. Diabetes Care. 2005;28(11):2662-7, https://doi.org/10.2337/diacare.28.11.2662.

29. Rees DI, Sabia JJ. Migraine Headache and Labor Market Outcomes. Health Econ. 2015;24(6):659-71, https://doi.org/ 10.1002/hec.3052.

30. Bertin P, Fagnani F, Duburcq A, Woronoff AS, Chauvin P, Cukierman $G$, et al. Impact of rheumatoid arthritis on career progression, productivity, and employability: The PRET Study. J Bone Spine. 2016;83(1):47-52, https://doi. org/10.1016/j.jbspin.2015.05.001.

31. Schuring M, Burdorf L, Kunst A, Mackenbach J. The effects of ill health on entering and maintaining paid employment: evidence in European countries. J Epidemiol Community Health. 2007;61(7):597-604, https://doi.org/10.1136/jech. 2006.047456.

32. Freeman A, Tyrovolas S, Koyanagi A, Chatterji S, Leonardi M, Ayuso-Mateos JL, et al. The role of socio-economic status in depression: results from the COURAGE (aging survey in Europe). BMC Public Health. 2016:1098, https:// doi.org/10.1186/s12889-016-3638-0.

33. World Health Organization. Innovative care for chronic conditions: Building blocks for action. Global Report [Internet]. Geneva: The Organization; 2002 [cited 2018 Sep 13]. Available from: https://www.who.int/chp/knowledge/publications/ icccreport/en/.

34. Van den Berg T, Schuring M, Avendano M, Mackenbach J, Burdorf A. The impact of ill health on exit from paid employment in Europe among older workers. Occup Environ Med. 2010;67(12):845-52, https://doi.org/10.1136/oem.2009. 051730 .

35. Alavinia SM, Burdorf A. Unemployment and retirement and ill-health: a cross-sectional analysis across European countries. Int Arch Occup Environ Health. 2008;82(1):3945, https://doi.org/10.1007/s00420-008-0304-6.

36. Karpansalo M, Manninen P, Kauhanen J, Lakka TA, Salonen JT. Perceived health as a predictor of early retirement. Scand J Work Environ Health. 2004;30(4):287-92, https:// doi.org/10.5271/sjweh.796.

37. Organisation for Economic Co-operation and Development [Internet]. Paris: The Organisation; 2016 [cited 2018 Sep 13]. [Ageing and Employment Policies-Statistics on average effective age of retirement - OECD]. Available from: http://www. oecd.org/els/emp/average-effective-age-of-retirement.htm.

38. Cai L. The relationship between health and labour force participation: Evidence from a panel data simultaneous equation model. Labour Econ. 2010;17(1):77-90, https://doi.org/ 10.2139/ssrn.995971.

39. Korpi T. Accumulating Disadvantage. Longitudinal Analyses of Unemployment and Physical Health in Representative Samples of the Swedish Population. Eur Sociol Rev. 
2001;17(3):255-73, https:/doi.org/https://doi.org/10.1093/esr/ 17.3.255.

40. Gallo WT, Bradley EH, Teng HM, Kasl SV. The effect of recurrent involuntary job loss on the depressive symptoms of older US workers. Int Arch Occup Environ Health. 2006;80(2): 109-16, https://doi.org/10.1007/s00420-006-0108-5.

41. Gannon B. The influence of economic incentives on reported disability status. Health Econ. 2009;18(7):743-59, https:// doi.org/10.1002/hec.1399.

42. Akashi-Ronquest N, Carrillo P, Dembling B, Stern S. Measuring the biases in self-reported disability status: evidence from aggregate data. Appl Econ Lett. 2011;18(11):1053-60, https://doi.org/10.1080/13504851.2010.524603.

43. Lindeboom M, Kerkhofs M. Health and work of the elderly: subjective health measures, reporting errors and endogeneity in the relationship between health and work. J Appl Econom. 2009;24(6):1024-46, https://doi.org/https://doi.org/ 10.1002/jae.1077.

44. Foitzek N, Ávila CC, Ivandic I, Bitenc Č, Cabello M, Gruber S, et al. What Persons with Chronic Health Conditions Need to Maintain or Return to Work - Results of an Online-Survey in Seven European Countries. Int J Environ Res Public Health. 2018;15(4):595, https://doi.org/10.3390/ijerph15040595.

45. Solomon C, Poole J, Palmer KT, Coggon D. Health-related job loss: findings from a community-based survey. Occup Environ Med. 2007;64(3):144-9, https://doi.org/10.1136/oem. 2006.026567.

46. Janssens H, Clays E, de Clercq B, de Bacquer D, Casini A, Kittel F, et al. Association between psychosocial characteristics of work and presenteeism: A cross-sectional study. Int J Occup Med Environ Health. 2016;29(2):331-44, https:/doi. org/10.13075/ijomeh.1896.00588.

47. Vlachou A, Stavroussi P, Roka O, Vasilou E, Papadimitriou D, Scaratti C, et al. Policy Guidelines for Effective Inclusion and Reintegration of People with Chronic Diseases in the Workplace: National and European Perspectives. Int J Environ Res Public Health. 2018;15(3):493, https://doi. org/10.3390/ijerph15030493.
48. Whooley MA, Kiefe CI, Chesney MA, Markovitz JH, Matthews K, Hulley SB. Depressive Symptoms, Unemployment, and Loss of Income. Arch Intern Med. 2002;162(22):2614, https://doi.org/10.1001/archinte.162.22.2614.

49. Stankunas M, Kalediene R, Starkuviene S, Kapustinskiene V. Duration of unemployment and depression: a cross-sectional survey in Lithuania. BMC Public Health. 2006;6(1):174, https://doi.org/0.1186/1471-2458-6-174.

50. Kikuchi Y, Nakaya M, Ikeda M, Okuzumi S, Takeda M, Nishi M. Relationship between job stress, temperament and depressive symptoms in female nurses. Int J Occup Med Environ Health. 2014;27(3):426-34, https://doi.org/10.2478/ s13382-014-0270-z.

51. Nourry N, Luc A, Lefebvre F, Sultan-Taïeb H, Béjean S. Psychosocial and organizational work environment of nurse managers and self-reported depressive symptoms: Crosssectional analysis from a cohort of nurse managers. Int $\mathrm{J}$ Occup Med Environ Health. 2014;27(2):252-69, https://doi. org/10.2478/s13382-014-0264-x.

52. Stanislavoviene J, Pajarskiene B, Jankauskas R, Veniute M. The psychosocial factors at work related to depression among female white-collar workers in Vilnius (Lithuania). Int J Occup Med Environ Health. 2011;24(2):166-76, https:// doi.org/10.2478/s13382-011-0018-y.

53. Saijo Y, Chiba S, Yoshioka E, Kawanishi Y, Nakagi Y, Itoh T, et al. Effects of work burden, job strain and support on depressive symptoms and burnout among Japanese physicians. Int J Occup Med Environ Health. 2014;27(6):98092, https://doi.org/10.2478/s13382-014-0324-2.

54. Esteban E, Coenen M, Ito E, Gruber S, Scaratti C, Leonardi M, et al. Views and Experiences of Persons with Chronic Diseases about Strategies that Aim to Integrate and Re-Integrate Them into Work: A Systematic Review of Qualitative Studies. Int J Environ Res Public Health. 2018;15(5):1022, https://doi.org/10.3390/ijerph15051022.

55. Muñoz-Murillo A, Esteban E, Ávila CC, Fheodoroff K, Haro JM, Leonardi M, et al. Furthering the Evidence of the Effectiveness of Employment Strategies for People 
with Mental Disorders in Europe: A Systematic Review. Int J Environ Res Public Health, 2018;15(5):838, https://doi. org/10.3390/ijerph15050838.

56. Pedersen J, Bjorner JB, Burr H, Christensen KB. Transitions between sickness absence, work, unemployment, and disability in Denmark 2004-2008. Scand J Work Environ Health. 2012;38(6):516-26, https://doi.org/10.5271/sjweh.3293.

57. Lee HW, Song M, Yang JJ, Kang D. Determinants of Poor Self-rated Health in Korean Adults With Diabetes. J Prev Med Public Health. 2015;48(6):287-300, https://doi. org/10.3961/jpmph.15.048.

58. Murali V, Oyebode F. Poverty, social inequality and mental health. Adv Psychiatr Treat. 2004;10(3):216-24, https://doi. org/10.1192/apt.10.3.216.
59. Wilkinson R, Marmot M. Social Determinants of Health: The Solid Facts, Second edition [Internet]. Copenhagen: World Health Organization; 2003 [cited 2019 Jun 15]. Avaliable from: https://apps.who.int/iris/handle/10665/108082.

60. Reeuwijk RG, van Klaveren D, van Rijn RM, Burdorf A, Robroek SJW. The influence of poor health on competing exit routes from paid employment among older workers in 11 European countries. Scand J Work Environ Health. 2017;43(1):24-33, https://doi.org/10.5271/sjweh.3601.

This work is available in Open Access model and licensed under a Creative Commons Attribution-NonCommercial 3.0 Poland License - http://creativecommons.org/ licenses/by-nc/3.0/pl/deed.en. 